\title{
HYPERTHYROIDISM; PREVALENCE IN ABBOTTABAD, PAKISTAN: A HOSPITAL BASED STUDY
}

1. Assistant Professor Department of Pathology, Frontier Medical \& Dental College, Abbottabad.

2. Assistant Professor, Department of Oral Biology, Frontier Medical \& Dental College, Abbottabad.

3. Assistant Professor,

Department of Oral Biology,

Women Medical \& Dental College, Abbottabad

4. Professor

Department of Pathology,

Frontier Medical \& Dental College, Abbottabad.

Correspondence Address: Dr. Muhammad Usman Anjum, Assistant Professor, Department Pathology,

Frontier Medical \& Dental College Abbottabad, Pakistan

usmanziyai@gmail.com

Article received on:

09/11/2015

Accepted for publication:

22/01/2016

Received after proof reading: 12/04/2016

\section{INTRODUCTION}

Thyroid disorders are quite prevalent worldwide and are believed to affect more than $\mathbf{3 0 0}$ million people globally. But, more than half of these patients are not aware of their disease. ${ }^{1}$ Thyroid dysfunction generally manifests in the form of either hyperthyroidism or hypothyroidism due to over or under-secretion of thyroid hormone, respectively. ${ }^{2}$ This is also associated with abnormalities of thyroid function tests (TFTs), such as thyrotropin (TSH) and thyroid hormones, (free triiodothyronine,fT3 and free thyoxine,fT4). ${ }^{1}$

Hyperthyroidism is a pathological condition which is characterized by excess of thyroid hormone in the circulation and is more common in women. ${ }^{3,4}$ The prevalence of subclinical and overt hyperthyroidism in south Asia is reported to be $1.6 \%$ and $1.3 \%$ respectively. ${ }^{5}$ Most common

\section{Dr. Muhammad Usman Anjum', Dr. Adil Umar Durrani², Dr. Talib Hussain ${ }^{3}$, Dr. Syed Humayun $\mathrm{Shah}^{4}$} ectives: Design: Descriptive cross-sectional study. Setting: Frontier Medical \& Dental College Abbottabad. Period: January to August, 2015. Methods: One hundred and twenty patients included in the study based on inclusion and exclusion criteria. Thyroid function tests (TSH, 13 \& 14 ) were pertormed using enzyme linked immunoassay (ELISA) method. Results: patients $(56.67 \%)$ were between the ares of $21-40$ years of age, with mean . Me of study population to be $32.09 \pm 13.01$ years. The prevalence of hyperthyroidism was $15 \%$ based on the hyperthyroid patients as compared to $3.15+2.23 \mathrm{mlU} / \mathrm{L}, 2.05 \pm 0.88 \mathrm{ng} / \mathrm{mL}$ and $10.69+2.69$ $\mu \mathrm{g} / \mathrm{dL}$ in euthyroid subjects. Conclusion: Thyroid disorders are not very rare among general population. TFTs provide a reliable way of ascertaining the thyroid function. As this is a hospital disorders in the community.

Key words: Hyperthyroidism, thyroid function tests.

Article Citation: Anjum MU, Durrani AU, Hussain T, Shah SH. Hyperthyroidism; prevalence in Abbottabad, Pakistan: a hospital based study. Professional Med J 2016;23(4):401-405. DOI: 10.17957/TPMJ/16.3159

cause of hyperthyroidism is Grave's disease followed by toxic multinodular and nodular goiter and thyroiditis. ${ }^{4,6}$ Symptoms associated with hyperthyroidism are anxiety and heat intolerance, palpitations, weight loss, fatigue and menstrual irregularities in women. ${ }^{3}$ Clinically, these patients can have lid lag, tachycardia, warm but moist skin and tremors. ${ }^{3,7}$ Hyperthyroidism can be diagnosed by thyroid function tests (raised fT3 \& fT4 and low TSH) and confirmed by thyroid isotope scan. $^{8}$ Different treatment modalities are available for patients suffering from hyperthyroidism depending upon the underlying cause of the disease. These options include antithyroid drugs, beta-blockers, radio iodine and surgery. $4,6,8$

Thyroid function tests are one of the most commonly prescribed endocrine tests in a clinical 
setting. ${ }^{9}$ They provide valuable information about the functioning of thyroid gland. They can help to ascertain the functioning status of the thyroid gland, that is whether it's functioning normally or not. ${ }^{10}$ Biochemical abnormality generally precedes the development of clinical disease. Similarly, symptoms and signs may be subtle or entirely absent in patients with thyroid disease. Therefore, thyroid dysfunction can be detected early using TFTs. ${ }^{11} \mathrm{TSH}$ is believed to be more sensitive test for thyroid function. It can be used as an initial screening test but its results can be misleading ${ }^{12}$. Therefore, thyroid hormone levels, especially fT4 levels, should be measured and interpreted together with TSH levels to get a clear picture of functioning of thyroid gland. . $^{9} 12$

We have conducted this study to investigate the association between patients, who were suspected of suffering from hyperthyroidism clinically, with their thyroid function tests, to identify that how many patients who were suspected to be hyperthyroid clinically were biochemically hyperthyroid.

\section{MATERIAL AND METHODS}

This was a hospital-based descriptive crosssectional study which was conducted in Frontier Medical \& Dental College, Abbottabad from January to August, 2015. Ethical approval was taken from institution's ethics review committee. There was a consecutive non-probabilistic sampling. All patients, of both genders, suspected of suffering from hyperthyroidism on clinical presentation were included in the study. Demographic data including age and gender was recorded. Patients who were taking treatment for thyroid disorder or already diagnosed with thyroid disease or suffering with thyroid malignancy were excluded from the study.

Thyroid function tests (TSH, fT3 \& fT4) were performed using enzyme linked immunoassay (ELISA) method. The normal reference range for $\mathrm{TSH}$, fT3 and fT4 were 0.4-6.0 mIU/L, 0.6-2.1 ng/ $\mathrm{mL}$ and 5-12.5 $\mu \mathrm{g} / \mathrm{dL}$. Patients were categorized into following categories, based on their TFT results: Euthyroid; (TFTs within normal reference range), hyperthyroid; (low TSH and high fT3 and fT4), subclinical hyperthyroid; (low TSH but fT3 and fT4 within normal reference range).

Statistical package for social sciences (SPSS version 17) was used to enter, organize and analyze data. It was presented in the form of mean \pm standard deviation and percentages.

\section{RESULTS}

There were 120 patients who were included in the study. Out of these 120 patients, there were 70 male and 50 female patients, with male to female ratio of 1.4:1, as shown in Figure-1.

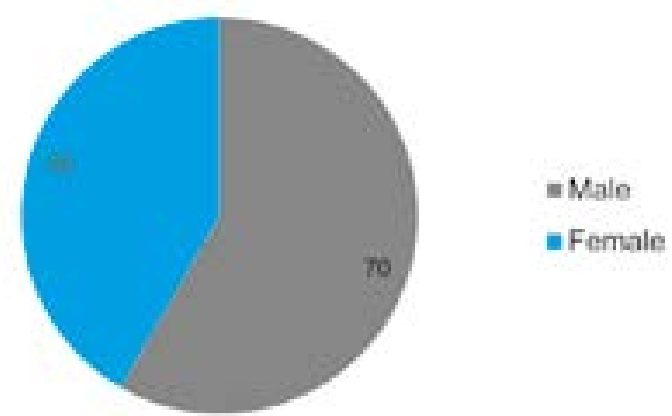

Figure-1. Gender-wise distribution of study population

Age-wise distribution of study subjects is shown in Table-l. It is evident that most of the patients (68) were in age group between 21-40, followed by 26 patients between the age of 41-60 and 22 patients were less than 20 years of age, showing higher predilection for younger age. The average age of patients was $32.09 \pm 13.01$ years.

\begin{tabular}{|c|c|c|}
\hline Age range (in years) & No of patients & Percentage \\
\hline$\leq 20$ & 22 & $18.33 \%$ \\
\hline $21-40$ & 68 & $56.67 \%$ \\
\hline $41-60$ & 26 & $21.67 \%$ \\
\hline$\geq 61$ & 4 & $3.33 \%$ \\
\hline Total & 120 & $100 \%$ \\
\hline Table-l. Age-wise distribution of study population, \\
(n=120)
\end{tabular}

There were 18 patients who were found to be hyperthyroid based on the results of their thyroid function tests. Out of these 18 patients, 11 were 
males and 7 were females with male to female ratio of 1.57:1, as shown in Table-II and III. The average age of patients was $25.72 \pm 8.27$ years.

\begin{tabular}{|l|c|c|}
\hline & No of Patients & Percentage \\
\hline Hyperthyroid Patients & 18 & $15 \%$ \\
\hline Euthyroid Patients & 102 & $85 \%$ \\
\hline Total & 120 & $100 \%$ \\
\hline
\end{tabular}

Table-II. No of hyperthyroid patients among study population, $(n=18)$

\begin{tabular}{|c|c|c|c|}
\hline Gender & $\begin{array}{c}\text { No of } \\
\text { Patients }\end{array}$ & $\begin{array}{c}\text { Hyperthyroid } \\
\text { patients }\end{array}$ & Percentage \\
\hline Male & 70 & 11 & $15.7 \%$ \\
\hline Female & 50 & 7 & $14 \%$ \\
\hline Total & 120 & 18 & $15 \%$ \\
\hline
\end{tabular}

Table-III. Gender wise stratification of hyperthyroid patients, $(n=18)$

Age-wise stratification of hyperthyroid patients is shown in Table-IV. Maximum number of patients, that is 10, were in age group 21-40 followed by 6 patients in age group of $\leq 20$ years.

\begin{tabular}{|c|c|c|c|}
\hline $\begin{array}{c}\text { Age range } \\
\text { (in years) }\end{array}$ & $\begin{array}{c}\text { No of } \\
\text { patients }\end{array}$ & $\begin{array}{c}\text { Hyperthyroid } \\
\text { patients }\end{array}$ & Percentage \\
\hline$\leq 20$ & 22 & 6 & $27.27 \%$ \\
\hline $21-40$ & 68 & 10 & $14.71 \%$ \\
\hline $41-60$ & 26 & 2 & $7.69 \%$ \\
\hline$\geq 61$ & 4 & - & - \\
\hline Total & 120 & 18 & \\
\hline Table-IV. Age-wise distribution of hyperthyroid \\
patients, (n=18)
\end{tabular}

Profile for thyroid function tests for both hyperthyroid and euthyroid patients is shown in Table-V.

\begin{tabular}{|c|c|c|c|c|}
\hline \multicolumn{2}{|c}{ Hyperthyroid, $(\mathbf{n = 1 8})$} & \multicolumn{2}{c|}{ Euthyroid, $(\mathbf{n = 1 0 2})$} \\
\hline Variable & Mean & STDEV & Mean & STDEV \\
\hline TSH, $(\mathrm{mlU} / \mathrm{L})$ & 0.038 & 0.025 & 3.15 & 2.23 \\
\hline $\mathrm{fT},(\mathrm{ng} / \mathrm{mL})$ & 7.08 & 2.19 & 2.05 & 0.88 \\
\hline fT4, $(\mu \mathrm{g} / \mathrm{dl})$ & 25.25 & 6.30 & 10.69 & 2.69 \\
\hline
\end{tabular}

Table-V. Thyroid profile of hyperthyroid and euthyroid patients, $(n=120)$

\section{DISCUSSION}

Thyroid disorders are one of the commonest endocrine disorders. Different factors, including nutritional and environmental ones, play an important role in thyroid disease causation. ${ }^{13}$ These factors also determine the prevalence of thyroid disorders. Most important among them is the availability of iodine. ${ }^{2,14}$ Both iodine deficiency and excess is believed to affect thyroid function. ${ }^{14}$, ${ }^{15}$ It is believed that iodine deficiency is the most common cause of thyroid disorders globally as about one third of world population reside in iodine deficient areas. ${ }^{2}$

The prevalence of hyperthyroidism was $15 \%$ in our study. This finding is similar to other studies. Baral et al have reported the same finding in their study which was conducted to study the prevalence of thyroid dysfunction in eastern Nepal. They have reported the incidence of hyperthyroidism to be $13.68 \%$ in their study. ${ }^{16}$ Similarly, Yadav et al have reported the incidence of hyperthyroidism to be $14.9 \%$ in western Nepal while Aryal et al have reported the incidence of total hyperthyroidism to be $9 \%$ in their study from Kavre, Nepal. ${ }^{1,2}$ But, there are other studies which have reported the different 'results. Paul et al have reported the incidence of total hyperthyroidism to be $1.51 \%$ in their study which was conducted in Khulna, Bangladesh. ${ }^{17}$

Unnikrishnan and Menon have reported the incidence of overt and subclinical hyperthyroidism $1.3 \%$ and $1.6 \%$ in community while $1.2 \%$ and $0.6 \%$ in hospital subjects in India. ${ }^{5}$ Likewise, Desai has reported the incidence of hyperthyroidism to be $2 \%$ in India. ${ }^{18}$ Similarly, Mahato et al have reported the incidence of total hyperthyroidism to be $4 \%$ in a hospital-based study conducted in central Nepal. ${ }^{19}$ Kutluturk et al have reported the incidence of total hyperthyroidism to be $5.4 \%$ in northern Turkey. ${ }^{20}$ This wide variation in the rate of prevalence of hyperthyroidism in different countries could be due to the variation in geographical area, environmental and nutritional factors, most importantly, presence or absence of iodine in the diet. 
The average age of hyperthyroid patients was $25.72 \pm 8.27$ years in our study. Highest numbers of hyperthyroid cases (10) were present between 21-40 years of age, which shows that the younger people are most commonly affected by thyroid diseases. This is same as reported by other studies. Yadav et all have reported the same finding in their study conducted in western Nepal. The majority of cases of thyroid dysfunction were between the age of 21-40 years. ${ }^{2}$ Paul et al have also observed that about $50 \%$ of cases of overt hyperthyroidism, in their study in Bangladesh, were between 16-30 years of age. ${ }^{17}$, In their study in Nepal, Baral et al have also reported that the highest number of cases of thyroid dysfunction were between 21-40 years of age. ${ }^{16}$ Similarly, Aryal et al have reported that the highest incidence of thyroid diseases were among the age group of 15-45 years. ${ }^{1}$ Der et al, in their study in Ghana, have reported that the maximum cases of thyroid dysfunction were between the age of 30-39 years. ${ }^{21}$ Mahato et al have also shown, in their study in central Nepal, that the maximum number of cases seen between the age of 3145 years. ${ }^{19}$ This shows that the thyroid disorders are becoming more prevalent among younger people.

The mean value of TSH, fT3 and fT4 was $0.038 \pm 0.025,7.08 \pm 2.19$ and $25.25 \pm 6.30$ in hyperthyroid patients respectively as compared to $3.15 \pm 2.23,2.05 \pm 0.88$ and $10.69 \pm 2.69$ in euthyroid subjects. This finding was comparable to the study conducted by Aryal et al in Nepal. They have reported that the value of TSH was $0.11 \pm 0.02 \mathrm{mIU} / \mathrm{mL}$ and that of fT3 was $6.09 \pm 0.38$ $\mathrm{pg} / \mathrm{mL}^{1}$. Therefore, TFTs play an important role in the diagnosis of thyroid disorders. They should be offered to any patient suspected of suffering from thyroid disease.

This is a hospital based study. It cannot be a true representation of actual prevalence of thyroid dysfunction in the community as a whole. It provides only limited information about the thyroid disorders. Therefore, we recommend that field and community based studies should be conducted to determine the precise frequency of thyroid disorders in the community as a whole. Availability of iodine in the area must be considered while planning such studies.

\section{CONCLUSION}

Thyroid disorders are not very rare among general population. TFTs provide a reliable way of ascertaining the thyroid function. As this is a hospital based study, field studies should be conducted to ascertain the true prevalence of thyroid disorders in the community.

Copyright (C) 22 Jan, 2016.

\section{REFERENCES}

1. Aryal M, Gyawali P, Rajbhandari N, Aryal P, Pandeya DR. A prevalence of thyroid dysfunction in Kathmandu University Hospital, Nepal. Biomedical Research. 2010;21:411-5.

2. Yadav NK, Thanpari C, Shrewastwa MK, Sathian B, Mittal RK. Socio demographic wise risk assessment of thyroid function abnormalities in far western region of Nepal: A hospital based descriptive study. Asian Pacific Journal of Tropical Disease. 2013;3(2):150-4.

3. Sharma M, Aronow WS, Patel L, Gandhi K, Desai H. Hyperthyroidism. Medical Science Monitor : International Medical Journal of Experimental and Clinical Research. 2011;17(4):RA85-RA91.

4. Franklyn JA, Boelaert K. Thyrotoxicosis. Lancet. 2012;379(9821):1155-66.

5. Unnikrishnan AG, Menon UV. Thyroid disorders in India: An epidemiological perspective. Indian Journal of Endocrinology and Metabolism. 2011;15(Suppl2):S78-S81.

6. Cooper DS. Hyperthyroidism. Lancet. 2003;362(9382):459-68.

7. Ahsan T, Banu Z, Jabeen R, Farooq MU. Clinical spectrum and various forms of thyrotoxcosis in endocrine clinic of Jinnah Postgraduate Medical Centre. Journal of Pakistan Medical Association. 2013;63(3):354-7.

8. Maji D. Hyperthyroidism. Journal of the Indian Medical Association. 2006;104(10):563-4, 6-7.

9. Huang $\mathrm{H}, \mathrm{Aw} \mathrm{T}$. Thyroid function testing - a review. Annals of Thyroid Research. 2014;1(2):17-22.

10. Koulouri O, Moran C, Halsall D, Chatterjee K, Gurnell $M$. Pitfalls in the measurement and interpretation 
of thyroid function tests. Best Practice \& Research Clinical Endocrinology \& Metabolism. 2013;27(6):74562.

11. Carvalho GAd, Perez CLS, Ward LS. Utilização dos testes de função tireoidiana na prática clínica. Arquivos Brasileiros de Endocrinologia \& Metabologia. 2013;57:193-204.

12. Beckett GJ. The investigation of thyroid function. Journal of the International Federation of Clinical Chemistry. 1995;6(5):186-90.

13. Ogbera AO, Kuku SF. Epidemiology of thyroid diseases in Africa. Indian Journal of Endocrinology and Metabolism. 2011;15(Suppl2):S82-S8.

14. Khatiwada S, Rajendra K, Sah SK, Khan SA, Chaudhari RK, Baral N, et al. Thyroid dysfunction and associated risk factors among nepalese diabetes mellitus patients. International Journal of Endocrinology. 2015;2015:5.

15. Khatiwada S, Gelal B, Shakya PR, Lamsal M, Baral N. Urinary iodine excretion among Nepalese school children in Terai region. The Indian Journal of Pediatrics. 2015:1-3.

16. Baral N, Lamsal M, Koner B, Koirala S. Thyroid dysfunction in eastern Nepal. Southeast Asian Journal of Tropical Medicine and Public Health. 2002;33(3):638-41.

17. Paul AK, Miah SR, Mamun AA, Islam S. Thyroid disorders in Khulna district: a community based study. Bangladesh Medical Research Council Bulletin. 2006;32(3):66-71.

18. Desai MP. Disorders of thyroid gland in India. Indian journal of pediatrics. 1997;64(1):11-20.

19. Mahato R, Jha B, Singh K, Yadav B, Shah S, Lamsal $M$. Status of thyroid disorders in central Nepal: a tertiary care hospital based study. International Journal of Applied Sciences and Biotechnology. 2015;3(1):119 - 22.

20. Kutluturk F, Yildirim B, Ozturk B, Ozyurt H, Bekar $U$, Sahin S, et al. Thyroid dysfunctions and sonographic characteristics in northern Turkey: a population-based study. Annals of Saudi Medicine. 2013;33(3):253-9.

21. Der E, Quayson S, Clegg-Lamptey J, Wiredu E, Ephraim R, Gyasi R. Thyroid disorders in Accra, Ghana: a retrospective histopathological study at the Korle-Bu teaching hospital. Journal of Medical and Biomedical Sciences. 2013;2(1).

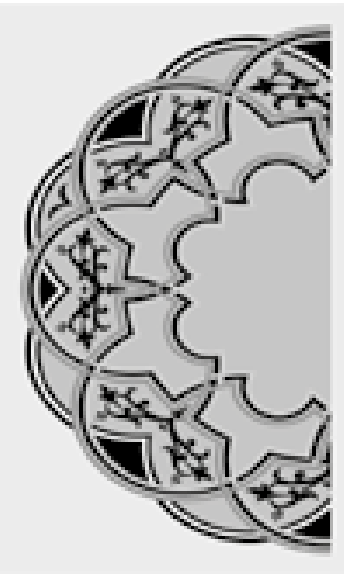

\section{"When you pray for rain, you gotta deal with mud too"}

\section{AUTHORSHIP AND CONTRIBUTION DECLARATION}

\begin{tabular}{|c|c|c|c|}
\hline Sr. \# & Author-s Full Name & Contribution to the paper & Author $=s$ Signature \\
\hline 1 & Dr. M. Usman Anjum & Performed study \& written & \\
\hline 2 & Dr. Adıl Umar Durranı & Co-author & \\
\hline 3 & Dr. Talib Hussain & Co-author & \\
\hline 4 & Dr. Syed Humayun Shah & $\begin{array}{l}\text { Conceive the idea, } \\
\text { Suppervised \& proof read } \\
\text { the manuscript }\end{array}$ & 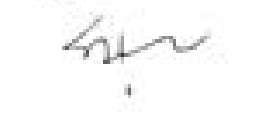 \\
\hline
\end{tabular}

